\title{
Application of Artificial Neural Network for Damage Detection in Planetary Gearbox of Wind Turbine
}

\author{
Marcin Strączkiewicz and Tomasz Barszcz \\ Department of Robotics and Mechatronics, Faculty of Mechanical Engineering and Robotics, AGH University of Science and Technology, \\ 30 Mickiewicza Avenue, 30-059 Krakow, Poland \\ Correspondence should be addressed to Marcin Strączkiewicz; mstr@agh.edu.pl
}

Received 3 July 2015; Revised 28 August 2015; Accepted 1 September 2015

Academic Editor: Dong Wang

Copyright (C) 2016 M. Strączkiewicz and T. Barszcz. This is an open access article distributed under the Creative Commons Attribution License, which permits unrestricted use, distribution, and reproduction in any medium, provided the original work is properly cited.

\begin{abstract}
In the monitoring process of wind turbines the utmost attention should be given to gearboxes. This conclusion is derived from numerous summary papers. They reveal that, on the one hand, gearboxes are one of the most fault susceptible elements in the drive-train and, on the other, the most expensive to replace. Although state-of-the-art CMS can usually provide advanced signal processing tools for extraction of diagnostic information, there are still many installations, where the diagnosis is based simply on the averaged wideband features like root-mean-square (RMS) or peak-peak (PP). Furthermore, for machinery working in highly changing operational conditions, like wind turbines, those estimators are strongly fluctuating, and this fluctuation is not linearly correlated to operation parameters. Thus, the sudden increase of a particular feature does not necessarily have to indicate the development of fault. To overcome this obstacle, it is proposed to detect a fault development with Artificial Neural Network (ANN) and further observation of linear regression parameters calculated on the estimation error between healthy and unknown condition. The proposed reasoning is presented on the real life example of ring gear fault in wind turbine's planetary gearbox.
\end{abstract}

\section{Introduction}

In recent years, large power planetary gearboxes became very popular elements of wind turbine's drive-trains due to their ability to transmit a relatively high load from blades simultaneously providing a high gear ratio, which is required for efficient production of electrical energy by the generator.

On the other hand, as it was pointed out in a number of statistical summaries [1-4], gearboxes (with no special distinction for the planetary ones and others) are located on top of the list of most damage susceptible drive-train components in this group of rotating machinery. This is one of the reasons why wind turbine gearboxes, and planetary ones in particular, received the utmost attention of researchers and maintenance engineers. In consequence, this initiated the pursuit for providing the methodology that could detect the damage at the early stage and therefore limit the downtime of the entire machine. It should be mentioned that, due to the sharing of load between several meshes during operation of a planetary gearbox, usually a single malfunction results in total gear damage requiring full gearbox replacement. According to [2], a $2.5 \mathrm{MW}$ wind turbine planetary gearbox replacement costs over $£ 400,000$, which significantly influences a total wind turbine revenue. Figure 1 presents such high power gearbox with two parallel stages and single planetary stage.

One of the possibilities for damage assessment of planetary gearboxes is vibration analysis. Unlike other typical monitored industrial objects, vibration analysis of such planetary gearboxes is generally more challenging. This is due to few reasons. Firstly, wind turbines inherently operate under nonstationary conditions, including variable speed and load. Therefore, analysis of its data requires advanced signal selection algorithms [5, 6] as well as sophisticated signal resampling methods [7]. Secondly, in order to maximize even teeth wear, planetary gearboxes are designed with maximum length of a full cycle (i.e., exact repeatable position of planets and all teeth). Thus, faults related to planets may manifest themselves differently upon measurements not covering entire cycles. Tertiary, due to relatively low speed of wind turbine planetary gearbox elements consequent in relatively 


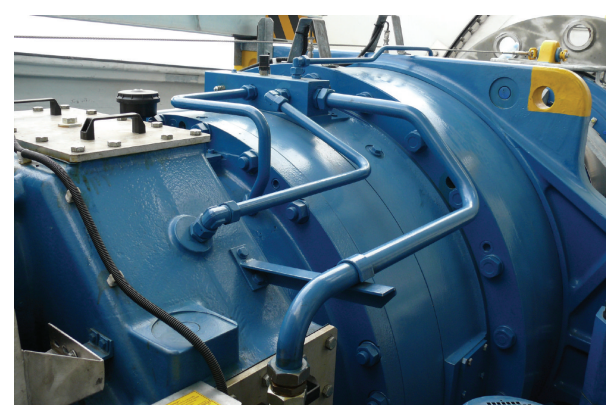

FIgURE 1: Planetary gearbox.

low characteristic frequencies, accurate fault identification requires extremely long records, which are difficult to store and analyze. Moreover, usually low speed results in low fault induced energy, which in turn requires high sensitivity and high quality data acquisition. Finally, commercial wind turbine manufacturers do not allow any mechanical interference into planetary gearbox casing, limiting signal sources to vibration recorded from outside a gearbox.

The first attempts to the vibration analysis of gears were performed in the early 80 s [8]. Over the years, a number of methods were developed; however many of them referred to analysis of spur gears [9-13] covering wide range of approaches like dynamic modelling [14, 15], wavelet transform [16], Wigner-Ville distribution [17], and Principal Component Analysis [18], just to name a few. The research interest in planetary gearboxes increased along with the computational and storage capabilities of modern CMS. This allowed providing methodology for detection of damage of a different nature, that is, spalling $[19,20]$ and pitting $[21,22]$, cracked tooth [23] and carrier [24], faulty planet gears [25, 26] and ring gears [27], and so forth. Zimroz and Bartkowiak [28] analyzed application of Principal Component Analysis and Canonical Discriminant Analysis with multidimensional matrix of variables for classification of planetary gearbox condition. This work was preceded by [29], where authors developed a method that takes advantage of highly varying operational parameters by relating gearbox's condition to susceptibility of diagnostic features to load. It has to be mentioned that the exhaustive list of references related to this topic can be found in the review papers like [30, 31].

Unfortunately, although many diagnostic methods were proposed, a lot of them suffer from shortcomings that prevent their industrial applications. In [32], the authors noticed a requirement for visual inspection of diagnostic results for comparative assessment between healthy and damaged condition. Jablonski and Barszcz [33] point that many of the approaches assume precise location of gears in time, which is impractical for the majority of commercial installation. It was also observed that for particular techniques the data analysis is performed without the inclusion of information about the unsteady conditions of work [28]. Finally, based on the experience of the authors of this paper, in many contemporary CMS, especially in SCADA-based systems, raw vibration signals are not available for the end user. This is due to the limited data transfer, like for remote WTs, where data transmission is utilized via GPRS connection and prevents transmission of data packages containing highly sampled vibration signals of long duration. In such applications, the condition monitoring process is performed entirely on the basis of simple diagnostic features, like root-mean-square or the amplitude of vibration.

In such case, these indicators are observed over time (in the so-called trends) for the potential increase that might provide information of the occurrence of a malfunction (e.g., [34]). The additional obstacle is a nonlinear correlation between the level of diagnostic indicators and the corresponding operating conditions. Therefore the assessment on the behavior of the indicators is difficult $[35,36]$. This demand for stationary or quasistationary conditions is rarely satisfied for quite large group of machines like wind turbines [37-39] or mining excavators [40].

The above issue may be overcome by introducing operational states of machine $[41,42]$. In this approach, each trend is tracked in a precalculated range of operational conditions. Moreover, operational states are used for data classification during the acquisition procedure and consequently in data analysis process. Such modes are selected in order to most accurately describe a particular machine. Furthermore, it is desired to define a state for which calculated trends show low (or the lowest there is) level of variation [42]. Such stability is required for reliable justification of alarm threshold value. Otherwise, that is, for high variability, sudden increase of estimator would cause false positive alarms, misleading in the process of condition monitoring. Unfortunately, as mentioned in [42], the methodology for this approach is in the early stage of development.

In this paper, the authors follow the idea of the comparative study of simple vibration features in highly nonstationary operating conditions. The proposed reasoning is based on backpropagation Artificial Neural Network (ANN) and linear regression that fit the estimation error in the function of selected operation parameter. According to the literature review, so far such solution has not been proposed to the failure detection process of planetary gearboxes. Good accuracy of ANN for condition monitoring was shown for rolling element bearings [43-45], spur gears [46], centrifugal pumps [47], and power transformers [48]. In [49] the author employed ANN for estimation of remaining useful life of bearings. Bahmanyar and Karami [50] applied ANN to voltage signals while Crivelli et al. [51] verified its efficiency for acoustic emission. An interesting approach was proposed by Zhang and Wang [52] where ANN is used to model the behavior of generator's bearing, yet this method was applied to slowly varying parameter, that is, temperature.

The technique proposed in this paper takes into consideration fluctuation of vibration signal features under highly varying operating parameters of speed and load. Firstly, the ANN is trained at the normal (referential) behavior of the machine. Then, for each upcoming unclassified observation, the given value of a feature is compared against the value estimated using the taught net. In case of the regular operation, the error in assessment is relatively small, and it would 


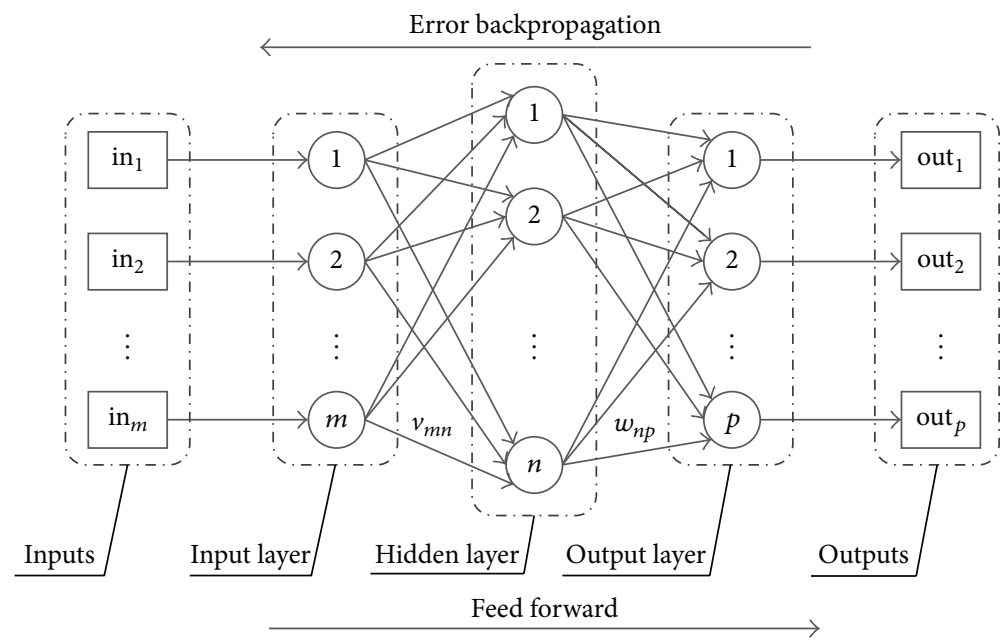

FIgURE 2: Scheme of Artificial Neural Network with backpropagation.

increase in case of arising malfunction. In order to limit the influence of changing conditions, the linear regression is employed and $b$ parameter (also called the error term) is observed. The method is presented on the case study example of planetary gearbox stationary ring fault that was not detected using classical trend analysis.

The paper is organized as follows. Within the introductory part, the state of the art of planetary gearbox diagnostics is presented and discussed with its shortcoming related to implementation in SCADA-based systems. The authors propose to use Artificial Neural Network and discuss its hitherto applications. Next, the principles of Artificial Neural Networks are described. The proposed fault detection approach is presented in Section 3. In Section 4, the usage of the method is shown in data acquired from commercially used wind turbine. Finally, the results are discussed and paper is concluded.

\section{Artificial Neural Networks}

The concept of backpropagation ANN was firstly proposed in [53]. It is constructed as a multilayer structure (Figure 2), containing three essential layers: input, hidden, and output, whereas the hidden layer might consist of multiple layers. The inputs $\mathrm{in}_{1}, \mathrm{in}_{2}, \ldots, \mathrm{in}_{m}$ information is passed to the unseen hidden layers with initial weights, generally described as $v_{m n}$ which corresponds to weight given to information between input neuron $m$ and hidden neuron $n$. In the process of a forward phase, the outputs out 1, out $_{2}, \ldots$, out $_{m}$ are calculated using different set of weights $w_{n p}$ between the hidden layer and the output layer. Then, the trained outputs are compared with the target ones and the error is established. In the following step, the error backpropagation is computed, which means that the weights are calibrated in order to minimize the estimation error for the entire set of training data. The last operation can be repeated in successive iterations called epochs, until the acceptable level of estimation error is established.

\section{The Proposed Algorithm}

As previously stated, the authors' intention is to present the method that takes into account process parameters, like oil temperature, wind, and rotational speed or load, and detect the increase of one or more of diagnostic features in the presence of fault development. In order to do that, the dependency on fluctuation of process parameters has to be reduced. It is possible due to the learning process of Artificial Neural Network that estimates a relationship between the input process parameters and the output diagnostic ones. The contribution of the paper is to use ANN as the model of the normal behavior of the vibration signal features, depending on the most important process variables, and later to use the trained model as the reference to the actual values of these features.

After establishing the network for the training set of inputs and outputs, the testing procedure can be performed. The net estimates values of diagnostic features based on given inputs. Next, this prediction is subtracted from the actual indication carried from CMS, resulting in estimation error. In fact, there are three reasons for the erroneous estimation.

The first one is the improper training of the neural network resulting in invalid output estimations of trained ANN for the unseen input. In this case, the estimation error changes with operational parameters, yet it stays at the similar level in time. In order to minimize this shortcoming, it is required to train the neural network using long time measurements that cover the entire range of operation parameters.

The second reason is related to the dynamics of the observed machine, that is, with unequivocal relation between operational parameters and diagnostic features. This happens when for a given combination of input parameters the output takes various values. In the training process of ANN such ambiguity is not possible to model since the taught net assigns a single value for each combination of inputs. It should be pointed out that, for the unchanged condition of machine, the estimation error related to imprecise training of ANN remains constant in time. 


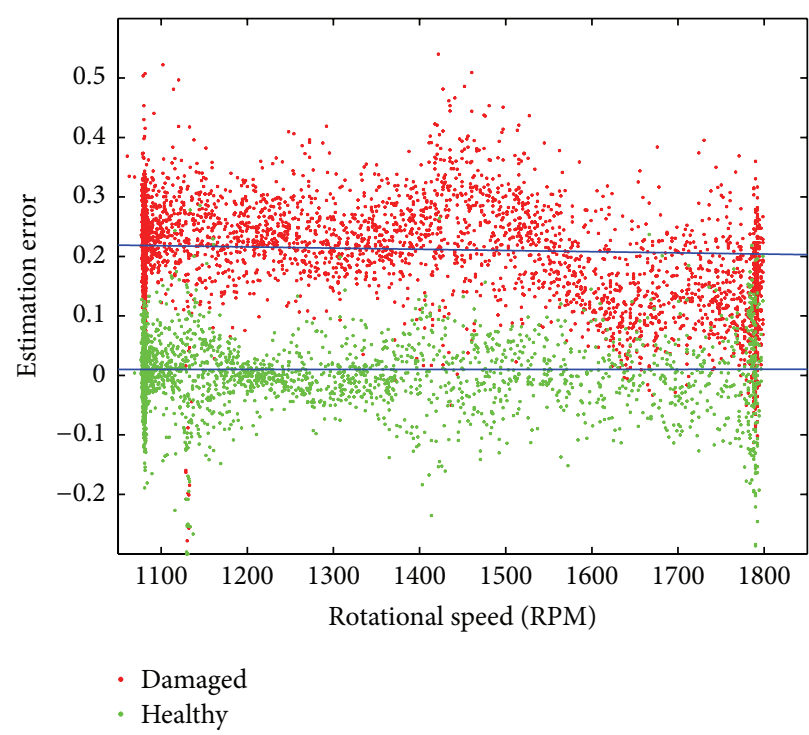

(a)

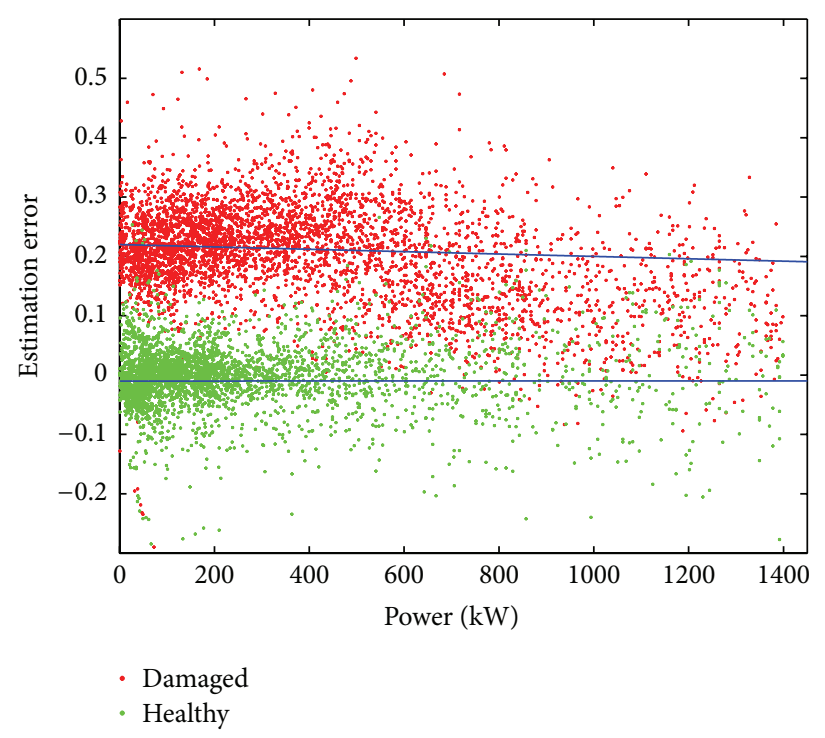

(b)

FIGURE 3: Exemplary regression analysis (blue) performed in two conditions: healthy (green) and damaged (red) plotted against operational parameters.

The third one appears when measured values do not correspond to those calculated in the referential period. This might indicate either sensor failure or, even more importantly, a damage development.

All of the aforementioned reasons might exist at the same time; therefore it is suggested to minimize its random influence and emphasize any deterministic phenomena. This can be done using the idea similar to the one presented in $[29,37]$. Zimroz et al. proposed to observe diagnostic features against chosen operational parameter in several segments obtained from trend plot. For each segment, the linear regression function is fit to the cloud of observations. The obtained parameters $a$ and $b$ are used for decision making process.

In the approach proposed in this paper, the linear regression is used to fit the estimation error in the function of selected operation parameter and not to the raw diagnostic features. It is based on the conclusion that in bad condition of machine the values of diagnostic features, and simultaneously the estimation error, would increase regardless of the change of operation conditions. Thanks to use of ANN, the dependency of error on operational parameters is limited, so the diagnostic reasoning can be limited simply to parameter $b$, also called the error term. For good condition, this parameter remains at low level (close to zero), and for bad condition it is significantly increased (Figure 3). In this case, threshold value may be established using statistical methods as presented, for example, in $[54,55]$, with no concern on highly changing operating conditions. Additionally, in order to improve the time domain resolution and hence accelerate the diagnostic decision, the segmentation may be performed with overlap [37]. In the proposed reasoning parameter $a$ is not taken into consideration since in general it is more susceptible to ambiguous association between inputs and output of ANN, and it is related to character of machine's operation. As presented in Figure 3, the distribution of error might be uneven in the domain of operational parameter, so it influences fitted regression line (marked in blue). Therefore it is concluded that parameter $a$ does not carry diagnostic information.

\section{Case Study}

4.1. Object Description. The proposed method is presented on the data acquired using vibration-based CMS installed on commercially utilized wind turbine (WT) located in western Germany. This 1.5 (MW) WT has a standard design of a drivetrain; that is, gearbox and generator are in line in the nacelle, as presented in Figure 3. The main rotor is driven by three blades and supported by the main bearing (A1). The planetary gearbox (A2) has three planets, which are impelled by the planet carrier. The planets roll over the ring and transmit the torque to the sun gear, simultaneously increasing the rotational speed. The sun shaft passes the torque from the planetary gear to the two-stage parallel gear (A3 and A4). The parallel gears have three shafts: the slow one that clutches to the sun shaft, the intermediate one, and the fast shaft, which drives the generator. The generator produces AC current of a varying frequency. It is firstly converted into DC and then into AC current of a frequency equal to the grid one. Electric transformations are performed by the controller located at the base of the WT's tower. In general, such drive-train multiplies the rotational speed from about 25 (RPM) on the main rotor to about 1800 (RPM) at the generator.

In the typical vibration-based CMS, it takes six sensors to collect data adequate for the proper diagnostics of the entire drive-train. They are located as presented in Figure 4: on main bearing (A1), on planetary gearbox (A2), on two parallel 


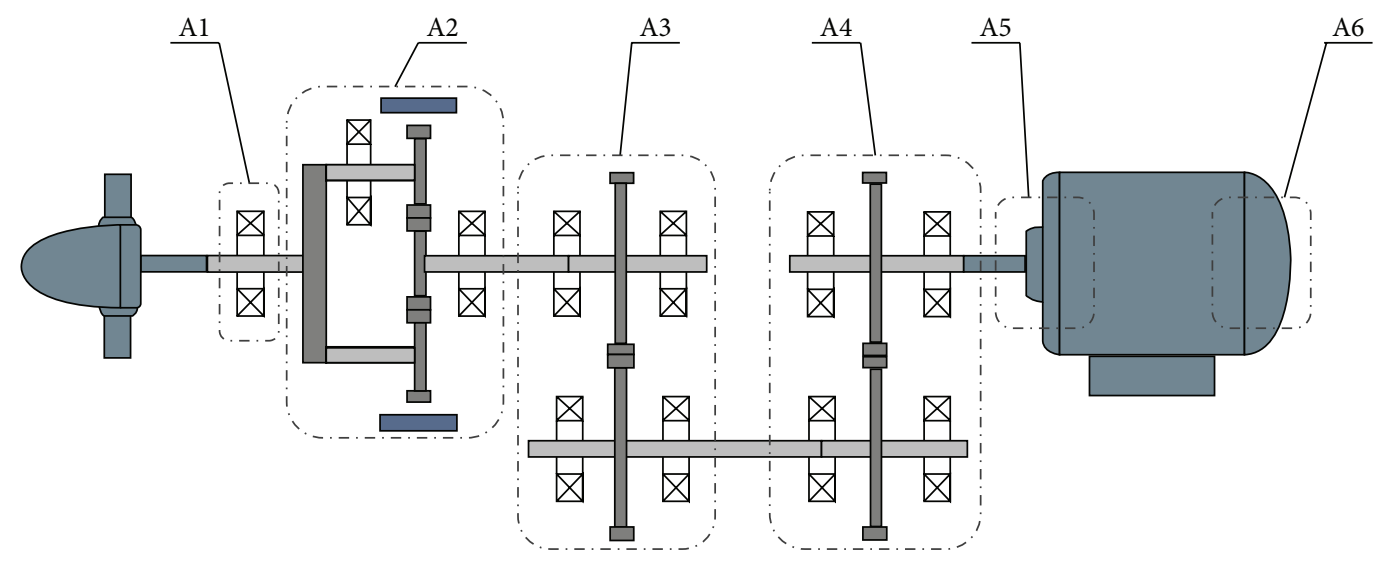

FIGURE 4: Kinematic scheme of the studied wind turbine.

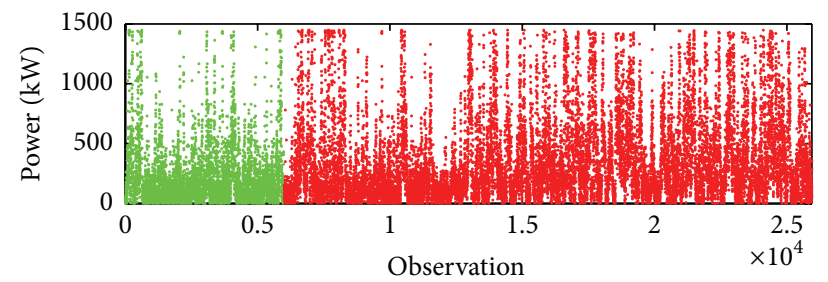

(a)

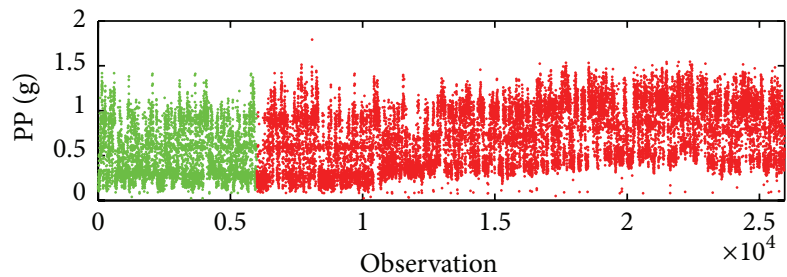

(c)

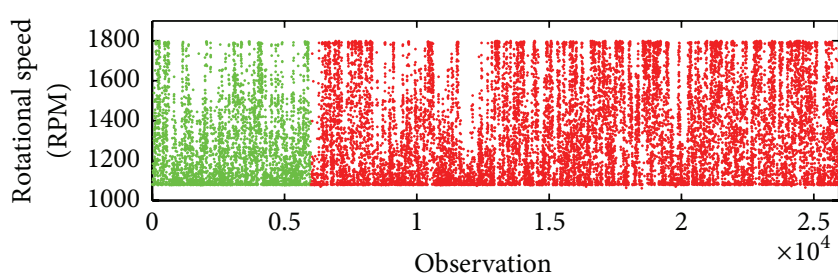

(b)

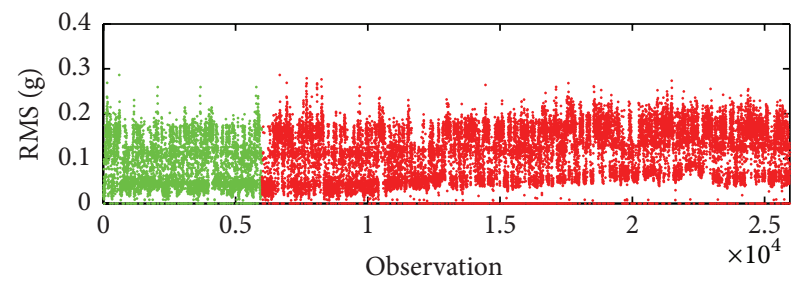

(d)

FIGURE 5: Observed parameters: power output (a), rotational speed (b), PP (c), and RMS of vibration signal from planetary gearbox (d). In green, data used for training; in red, data used for testing.

gearboxes (A3 and A4), and on the generator bearings (driven end (A5) and nondriven end (A6)).

As listed in [56], for machine with similar construction, nearly 150 indicators are extracted for the purpose of condition monitoring. The data is collected together with the corresponding operating parameters, namely, load and rotational speed.

In the described CMS, each parameter was acquired every 15 minutes from 10 (s) measurements. The vibration signals were collected with $25 \mathrm{kHz}$ of sampling frequency. Process parameters were recorded simultaneously to vibration signal at rate of once per second, so that 10 measurements were collected for each vibration signal. In the next step, these values were averaged, so that, as the output, the end user of the system received one value per observation for each of the parameters. It should be mentioned that, before the procedure of feature extraction, the validation of signals was performed according to the guideline proposed in [5]. It included partial filtration of data for low rotational speed (below 1050 (RPM)) and periods where load was below $0(\mathrm{~kW})$, that is, when wind turbine did not generate power.

In the presented case study, the wind turbine was observed for about 13 months-from the time of CMS installation until its stoppage for gearbox replacement. In total, about 38500 observations were recorded out of which about 26000 satisfied the validation requirement mentioned above. In the meantime, the extended wear of ring gear was developed. This phenomenon was not detected by CMS, yet it was found during periodical service measurements around observation 22500. In Figure 5, one can observe frequent changes of the operational state, although slight increase of wideband features was visible. The increase is only a small percent, and so typical approach for setting a threshold will not work, since it is based on the empirical distribution function [54].

The authors would like to discuss the approach based on ANN and linear regression that could reveal fault development in this gearbox. The data used for the proposed 


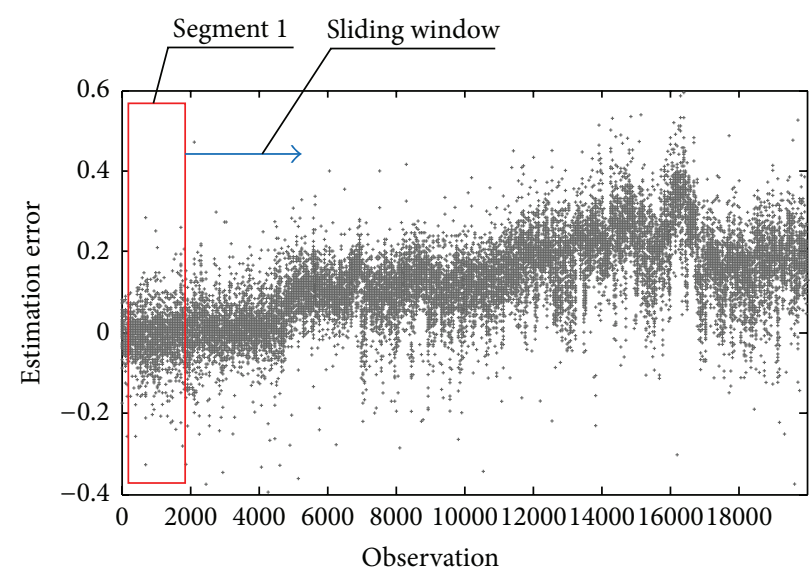

FIGURE 6: Estimation error with marked segment 1 (red) and sliding window (blue).

algorithm include two process parameters, namely, rotational speed of the generator's shaft and generator's output power, understood as load. There is a large number of features, which are calculated from raw vibration signals. Most popular ones are narrowband energies representing frequencies equal to gear mesh, shaft harmonics, and so forth. There are also broadband features, which are less susceptible to noise and windowing effects and are considered more robust ones. This is the main reason why it has been normalized and is used as an industry standard [57]. Two diagnostic features were selected, namely, root-mean-square (RMS) and peak-peak (PP).

4.2. Construction of ANN. One of the most important problems in condition monitoring of machinery in highly changing operational conditions is a nonlinear influence of such conditions, in particular rotational speed and load, on the level of vibration and thus on the fault indicators. It is often observed that the increase in amplitude related to changing conditions is much higher than the one created by a machinery fault, especially in its early stage. In the authors' opinion, one of the possible methods to reduce this problem is the use of ANN. In this approach, the network is trained using data collected in the referential (healthy) period of machine's operation and then used for estimation of values in the testing period, when the condition of machine is unknown. In the beginning of the investigation, a number of combinations for the ANN structure were tested. This resulted in conclusion that the least erroneous estimation is obtained using the 2-10-20-2 combination of nodes with mean square error equal to 0.0144 for PP and 0.0025 for RMS. The structure described as 2-10-20-2 means that two nodes were used as inputs (i.e., rotational speed and load); there were two hidden layers consisting of 10 and 20 nodes, respectively. Finally, the RMS and PP indicators were employed as the output (target) values.

4.2.1. Training. The proposed network was trained using about 3 months of observation (Figure 5), which amounted to about 6000 samples for each parameter. As mentioned previously, the rotational speed and load (power output) were treated as input parameters for training of the network, since it can be stated that it mostly influences the diagnostic parameters [29]. The RMS and PP were used as outputs.

The training on the given structure took place in 500 repetitions (epochs), during which the initial weights were corrected for minimizing the output error of prediction in the process of backpropagation (Figure 2). Finally the established net was used for the remaining data for possible damage detection.

4.2.2. Testing. The testing set covered about 20000 observations for each of the selected features, as presented in Figure 5. The input data were used by the established net of RMS and PP as outputs in order to achieve estimations of these parameters in the substantial time of the unknown operation. In the next step, the approximations were compared with the values calculated from the actual vibration signals recorded by CMS. Thanks to this procedure, the error of the estimation was obtained.

4.2.3. Linear Regression Fitting. In the next step, the data was divided into overlapping segments (overlap was equal to 50\%), each containing 2000 observations (Figure 6).

In Figures 7 and 8 one may observe distribution of estimation error against two operating parameters for PP and RMS, respectively. It can be seen that errors increase regardless of speed and load, yet they do not separate entirely from the initial segment. This is due to the small increase of diagnostic features in the initially observed trends and it prevents using classical methodology based on thresholds.

4.3. Fault Recognition. In the next step, for each segment linear regression was fit using least squares approach and parameters $a$ and $b$ were obtained and presented in Tables 1 and 2. Additionally, it is plotted in Figures 9 and 10. It can be seen that parameter $a$ does not change significantly regardless 

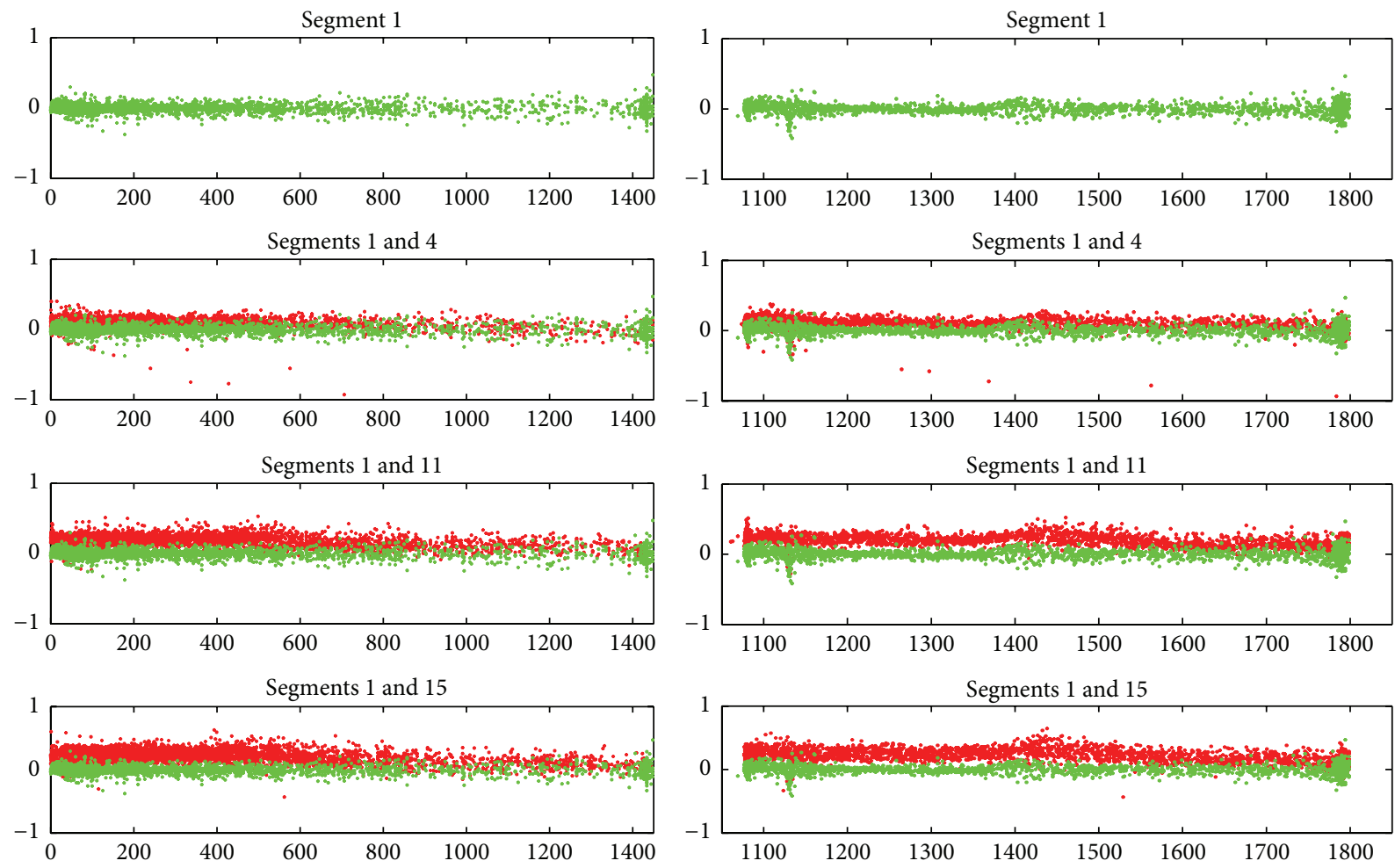

(a)

(b)

FIGURE 7: Regression of PP estimation error on segment 1 (green) and selected following segments (red) in function of power (a) and rotational speed (b).
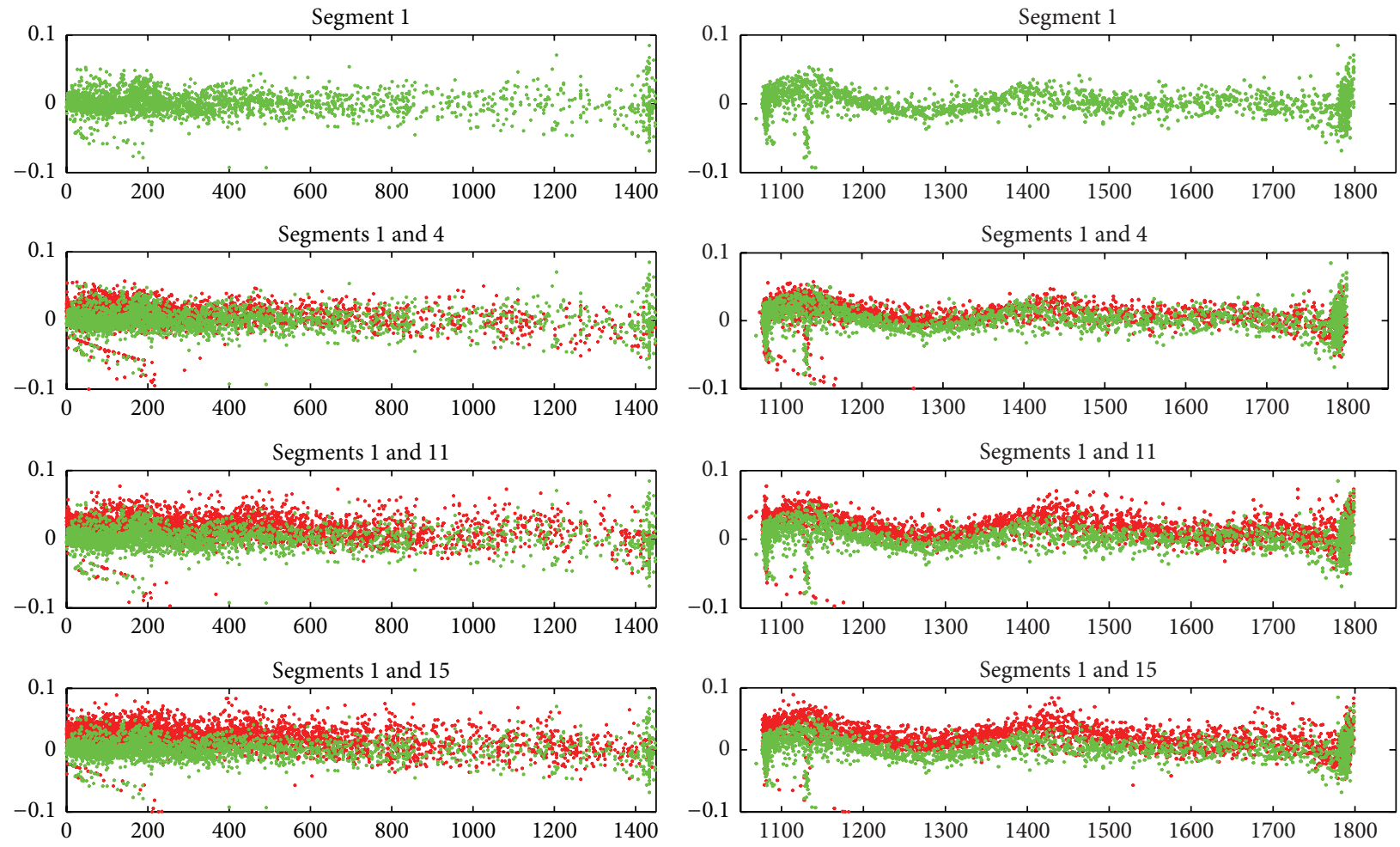

(a)

(b)

FIGURE 8: Regression of RMS estimation error on segment 1 (green) and selected following segments (red) in function of power (a) and rotational speed (b). 
TABLE 1: Regression parameters $a$ and $b$ for PP feature.

\begin{tabular}{lcccc}
\hline \multirow{2}{*}{ Number of segment } & \multicolumn{2}{c}{ Regression as a function of load } & \multicolumn{2}{c}{ Regression as a function of speed } \\
\hline 1 & $a$ & -0.0003 & $a$ \\
2 & $-1.5766 e-05$ & 0.0430 & $-1.6381 e-05$ & 0.0029 \\
3 & $-1.5483 e-05$ & 0.0697 & $-1.7524 e-05$ & 0.0239 \\
4 & $4.2233 e-06$ & 0.1115 & $5.8440 e-06$ & $1.8195 e-05$ \\
5 & $1.2853 e-05$ & 0.1173 & $1.7271 e-05$ & 0.1817 \\
6 & $1.1192 e-05$ & 0.1326 & $1.5953 e-05$ & 0.1861 \\
7 & $1.0557 e-05$ & 0.1394 & $2.9331 e-06$ \\
8 & $-1.2469 e-07$ & 0.1403 & $-3.7741 e-05$ \\
9 & $-3.1138 e-05$ & 0.1554 & $-6.4024 e-05$ \\
10 & $-6.1005 e-05$ & 0.1652 & $-9.2298 e-05$ \\
11 & $-7.9284 e-05$ & 0.1922 & $-9.3476 e-05$ \\
12 & $-7.8454 e-05$ & 0.2298 & $-8.2785 e-05$ \\
13 & $-6.9781 e-05$ & 0.2496 & $-9.4870 e-05$ \\
14 & $-7.3974 e-05$ & 0.2664 & $-1.1258 e-04$ \\
15 & $-8.8399 e-05$ & 0.2748 & $-1.2264 e-04$ \\
16 & $-9.5407 e-05$ & 0.2629 & $-1.5154 e-04$ \\
17 & $-1.1561 e-04$ & 0.2471 & $-1.3672 e-04$ & 0.2510 \\
18 & $-1.1373 e-04$ & 0.2261 & $-1.2909 e-04$ & 0.2474 \\
\hline
\end{tabular}

TABLE 2: Regression parameters $a$ and $b$ for RMS feature.

\begin{tabular}{|c|c|c|c|c|}
\hline \multirow{2}{*}{ Number of segment } & \multicolumn{2}{|c|}{ Regression as a function of load } & \multicolumn{2}{|c|}{ Regression as a function of speed } \\
\hline & $a$ & $b$ & $a$ & $b$ \\
\hline 1 & $4.3312 e-07$ & 0.0008 & $6.8457 e-08$ & 0.0044 \\
\hline 2 & $2.4075 e-06$ & 0.0057 & $1.1940 e-06$ & 0.0109 \\
\hline 3 & $9.2405 e-06$ & 0.0081 & $8.9710 e-06$ & 0.0172 \\
\hline 4 & $1.0180 e-05$ & 0.0115 & $9.6781 e-06$ & 0.0311 \\
\hline 5 & $7.9734 e-06$ & 0.0117 & $6.5334 e-06$ & 0.0348 \\
\hline 6 & $9.1124 e-06$ & 0.0130 & $7.0332 e-06$ & 0.0427 \\
\hline 7 & $2.1228 e-06$ & 0.0130 & $-1.8971 e-07$ & 0.0452 \\
\hline 8 & $-5.3487 e-06$ & 0.0122 & $-8.3286 e-06$ & 0.0433 \\
\hline 9 & $-9.1654 e-06$ & 0.0132 & $-1.4587 e-05$ & 0.0396 \\
\hline 10 & $-1.0978 e-05$ & 0.0140 & $-1.8990 e-05$ & 0.0355 \\
\hline 11 & $-1.0032 e-05$ & 0.0173 & $-1.8843 e-05$ & 0.0368 \\
\hline 12 & $-6.7979 e-06$ & 0.0223 & $-1.5419 e-05$ & 0.0442 \\
\hline 13 & $-5.6093 e-06$ & 0.0247 & $-1.2386 e-05$ & 0.0451 \\
\hline 14 & $-8.2130 e-06$ & 0.0267 & $-1.4679 e-05$ & 0.0502 \\
\hline 15 & $-5.8187 e-06$ & 0.0287 & $-1.2387 e-05$ & 0.0555 \\
\hline 16 & $-9.0436 e-06$ & 0.0276 & $-1.7583 e-05$ & 0.0545 \\
\hline 17 & $-8.4208 e-06$ & 0.0261 & $-1.6874 e-05$ & 0.0563 \\
\hline 18 & $-6.8415 e-06$ & 0.0237 & $-1.5494 e-05$ & 0.0516 \\
\hline
\end{tabular}

of the diagnostic indicator and operation parameter used for regression analysis. In each case, the oscillation around zero indicates even level of estimation error.

On the other hand, for parameter $b$ the difference between initial and deteriorating condition of ring gear is significant. It is clear that the increase is higher using this parameter when compared to trend of diagnostic feature alone. Moreover it is now possible to establish the control limit.

It is important to mention that the observed increase is not related to selected operating parameter, yet it is higher when observed in speed domain. This might be due to the wind turbine's design, which aims at establishing rotational 

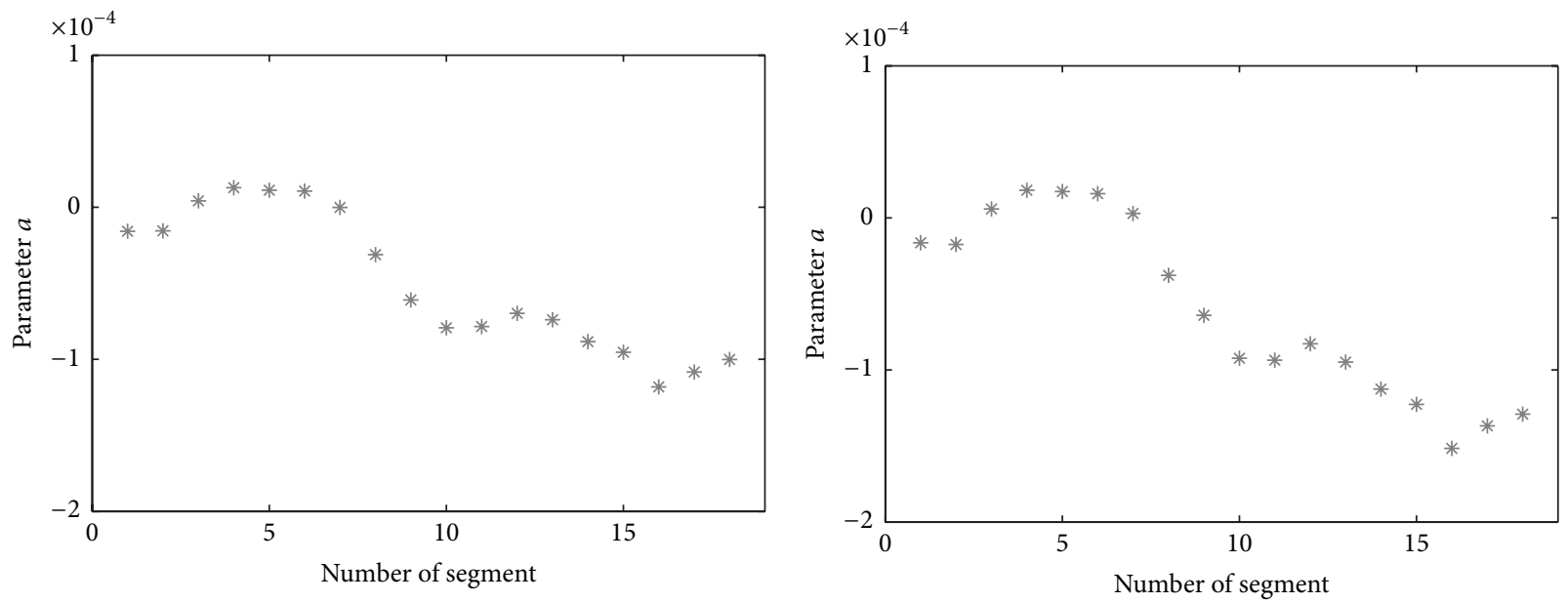

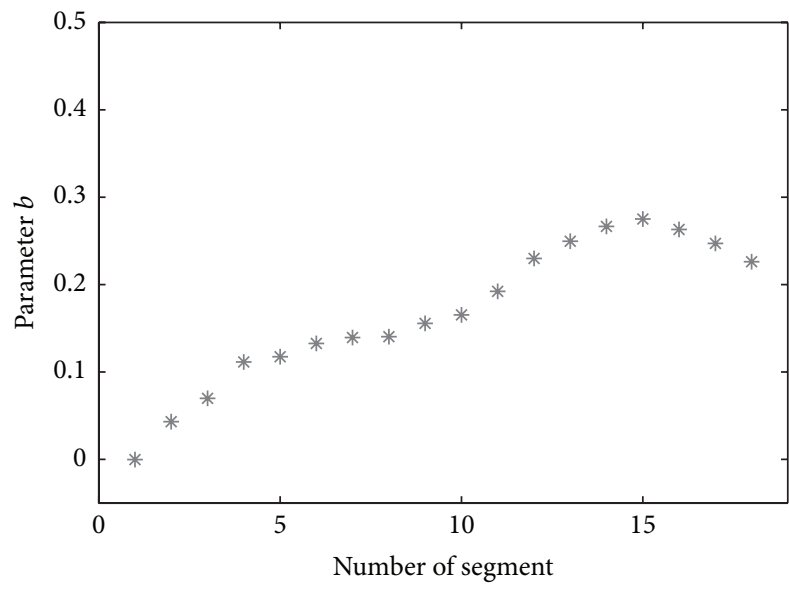

(a)

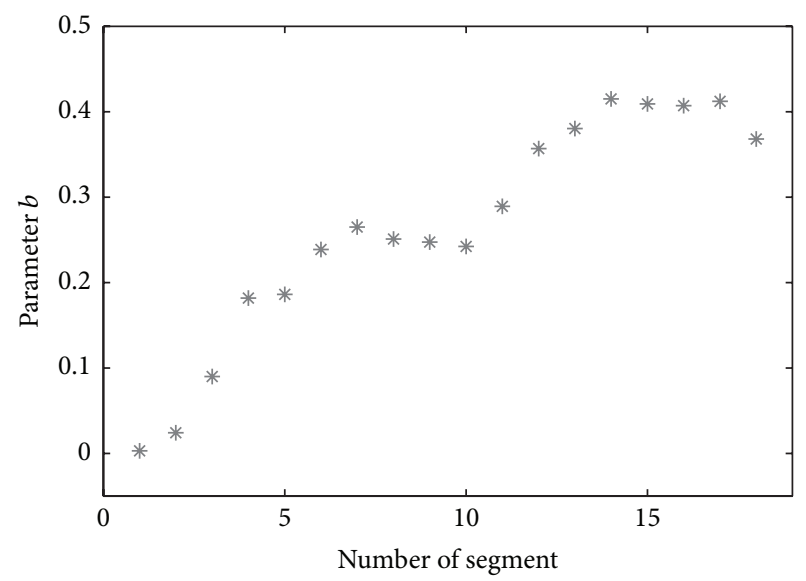

(b)

FIGURE 9: Fluctuation of parameters $a$ and $b$ obtained for consecutive segments of estimation error on PP over power (a) and rotational speed (b).

speed at certain levels (typically low and high). The arising error in estimation cumulates in few clouds around these speeds and influence the regression analysis. In the authors' opinion, this should not be considered as a drawback of a technique since it emphasizes arising malfunction.

\section{Conclusions}

Within the research paper, the application of backpropagation Artificial Neural Networks was investigated for detection of fault in wind turbine's planetary gearbox. ANN modelled the selected features depending on operational parameters and linear regression was later used to distinguish between the healthy and damaged state.

The analysis was focused on two commonly used diagnostic features, namely, root-mean-square (RMS) and peakpeak (PP). In the presented case study, it was shown that these indicators did not reveal sufficient symptoms of failure occurrence. To the contrary, the presented methodology exposed early stage of damage several months before gearbox replacement. This was possible by trending the erroneous estimation of diagnostic features and further fitting of linear regression in function of operation parameters. Thanks to the ability of ANN to model nonlinear dependencies, it was possible to reduce difficulties related to constantly and highly varying operating parameters. Parameter $b$ of linear regression provided information about general increase of error for the entire range of operating parameter and hence provided information of the development of damage in gearbox.

The additional benefit of the proposed approach is that it can be used with various input parameters and fault indicators. The method does not require preceding filtration of data, so there is no need for operational state setup. Clear distinction between initial and deteriorating condition makes it possible to establish a control limit and therefore automatize the diagnostic process. In the authors' opinion, it shows great potential for application in condition monitoring of various rotating machinery, such as wind turbines (as presented), mining excavators, or gas turbines.

\section{Conflict of Interests}

The authors declare that there is no conflict of interests regarding the publication of this paper. 

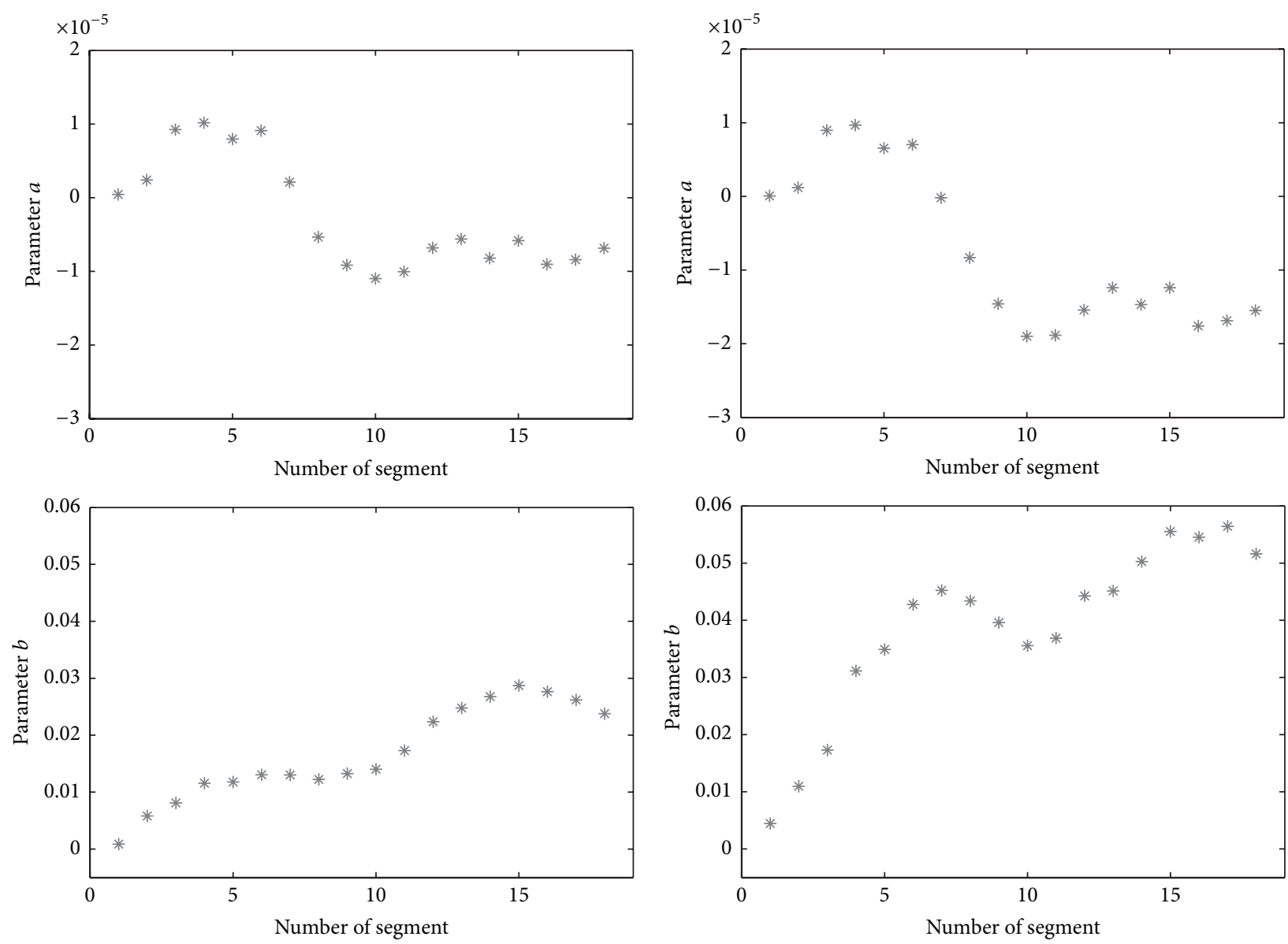

(a)

(b)

Figure 10: Fluctuation of parameters $a$ and $b$ obtained for consecutive segments of estimation error on RMS over power (a) and rotational speed (b).

\section{Acknowledgment}

The authors would like to acknowledge the financial support of AGH University of Science and Technology within the program of Dean's Scholarships (no. 15.11.130 987).

\section{References}

[1] G. W. Van Bussel and M. B. Zaaijer, "Reliability, availability and maintenance aspects of large-scale offshore wind farms," in Proceedings of the International Conference on Marine Renewable Energy, pp. 119-126, Newcastle, UK, 2001.

[2] D. McMillan and G. W. Ault, "Quantification of condition monitoring benefit for offshore wind turbines," Wind Engineering, vol. 31, no. 4, pp. 267-285, 2007.

[3] J. Ribrant and L. M. Bertling, "Survey of failures in wind power systems with focus on Swedish wind power plants during 19972005," IEEE Transactions on Energy Conversion, vol. 22, no. 1, pp. 167-173, 2007.

[4] S. Faulstich, B. Hahn, and P. J. Tavner, "Wind turbine downtime and its importance for offshore deployment," Wind Energy, vol. 14, no. 3, pp. 327-337, 2011.
[5] A. Jablonski and T. Barszcz, "Validation of vibration measurements for heavy duty machinery diagnostics," Mechanical Systems and Signal Processing, vol. 38, no. 1, pp. 248-263, 2013.

[6] G. Song, Z.-Y. Li, P. Bellemain, N. Martin, and C. Mailhes, "AStrion data validation of non-stationary wind turbine signals," in Proceedings of the 12th International Conference on Condition Monitoring and Machinery Failure Prevention Technologies, Oxford, UK, June 2015.

[7] L. F. Villa, A. Reñones, J. R. Perán, and L. J. de Miguel, "Angular resampling for vibration analysis in wind turbines under non-linear speed fluctuation," Mechanical Systems and Signal Processing, vol. 25, no. 6, pp. 2157-2168, 2011.

[8] R. B. Randall, "A new method of modeling gear faults," ASME Journal of Mechanical Design, vol. 104, no. 2, pp. 259-267, 1982.

[9] P. D. McFadden, "Determining the location of a fatigue crack in a gear from the phase of the change in the meshing vibration," Mechanical Systems and Signal Processing, vol. 2, no. 4, pp. 403409, 1988.

[10] J. D. Smith, Gear Noise and Vibration, Marcel Dekker, New York, NY, USA, 2nd edition, 2003.

[11] J. Mączak, "Local meshing plane as a source of diagnostic information for monitoring the evolution of gear faults," in Engineering Asset Lifecycle Management: Proceedings of the 4th World Congress on Engineering Asset Management (WCEAM 
2009), 28-30 September 2009, pp. 661-670, Springer, London, UK, 2010.

[12] A. Belsak and J. Flasker, "Method for detecting fatigue crack in gears," Theoretical and Applied Fracture Mechanics, vol. 46, no. 2, pp. 105-113, 2006.

[13] W. J. Staszewski and G. R. Tomlinson, "Application of the wavelet transform to fault detection in a spur gear," Mechanical Systems and Signal Processing, vol. 8, no. 3, pp. 289-307, 1994.

[14] I. Howard, S. Jia, and J. Wang, "The dynamic modelling of a spur gear in mesh including friction and a crack," Mechanical Systems and Signal Processing, vol. 15, no. 5, pp. 831-853, 2001.

[15] W. Bartelmus, "Gearbox dynamic modelling," Journal of Theoretical and Applied Mechanics, vol. 39, no. 4, pp. 989-999, 2001.

[16] W. J. Wang and P. D. McFadden, "Application of wavelets to gearbox vibration signals for fault detection," Journal of Sound and Vibration, vol. 192, no. 5, pp. 927-939, 1996.

[17] W. J. Staszewski, K. Worden, and G. R. Tomlinson, "Timefrequency analysis in gearbox fault detection using the WignerVille distribution and pattern recognition," Mechanical Systems and Signal Processing, vol. 11, no. 5, pp. 673-692, 1997.

[18] R. Zimroz and A. Bartkowiak, "Investigation on spectral structure of gearbox vibration signals by principal component analysis for condition monitoring purposes," Journal of Physics: Conference Series, vol. 305, Article ID 012075, pp. 1-11, 2011.

[19] P. D. Samuel and D. J. Pines, "A review of vibration-based techniques for helicopter transmission diagnostics," Journal of Sound and Vibration, vol. 282, no. 1-2, pp. 475-508, 2005.

[20] P. D. Samuel and D. J. Pines, "Constrained adaptive lifting and the CAL4 metric for helicopter transmission diagnostics," Journal of Sound and Vibration, vol. 319, no. 1-2, pp. 698-718, 2009.

[21] X. Zhao, M. J. Zuo, and Z. Liu, "Diagnosis of pitting damage levels of planet gears based on ordinal ranking," in Proceedings of the 2011 IEEE Conference on Prognostics and Health Management, pp. 1-8, Denver, Colo, USA, June 2011.

[22] Z. Cheng, N. Hu, F. Gu, and G. Qin, "Pitting damage levels estimation for planetary gear sets based on model simulation and grey relational analysis," Transactions of the Canadian Society for Mechanical Engineering, vol. 35, no. 3, pp. 403-417, 2011.

[23] Z. Chen, Z. Zhu, and Y. Shao, "Fault feature analysis of planetary gear system with tooth root crack and flexible ring gear rim," Engineering Failure Analysis, vol. 49, pp. 92-103, 2015.

[24] D. M. Blunt and J. A. Keller, "Detection of a fatigue crack in a UH-60A planet gear carrier using vibration analysis," Mechanical Systems and Signal Processing, vol. 20, no. 8, pp. 2095-2111, 2006.

[25] X. Zhao, M. J. Zuo, Z. Liu, and M. R. Hoseini, "Diagnosis of artificially created surface damage levels of planet gear teeth using ordinal ranking," Measurement, vol. 46, no. 1, pp. 132-144, 2013.

[26] J. P. T. Koch and C. M. Vicuña, "Dynamic and phenomenological vibration models for failure prediction on planet gears of planetary gearboxes," Journal of the Brazilian Society of Mechanical Sciences and Engineering, vol. 36, no. 3, pp. 533-545, 2014.

[27] T. Barszcz and R. B. Randall, "Application of spectral kurtosis for detection of a tooth crack in the planetary gear of a wind turbine," Mechanical Systems and Signal Processing, vol. 23, no. 4, pp. 1352-1365, 2009.
[28] R. Zimroz and A. Bartkowiak, "Two simple multivariate procedures for monitoring planetary gearboxes in non-stationary operating conditions," Mechanical Systems and Signal Processing, vol. 38, no. 1, pp. 237-247, 2013.

[29] W. Bartelmus and R. Zimroz, "A new feature for monitoring the condition of gearboxes in non-stationary operating conditions," Mechanical Systems and Signal Processing, vol. 23, no. 5, pp. $1528-1534,2009$.

[30] Y. Lei, J. Lin, M. J. Zuo, and Z. He, "Condition monitoring and fault diagnosis of planetary gearboxes: a review," Measurement, vol. 48, no. 1, pp. 292-305, 2014.

[31] A. K. S. Jardine, D. Lin, and D. Banjevic, "A review on machinery diagnostics and prognostics implementing condition-based maintenance," Mechanical Systems and Signal Processing, vol. 20, no. 7, pp. 1483-1510, 2006.

[32] Y. Lei, D. Kong, J. Lin, and M. J. Zuo, "Fault detection of planetary gearboxes using new diagnostic parameters," Measurement Science and Technology, vol. 23, no. 5, Article ID 055605, 2012.

[33] A. Jablonski and T. Barszcz, "Instantaneous circular pitch cyclic power (ICPCP) - a tool for diagnosis of planetary gearboxes," Key Engineering Materials, vol. 518, pp. 168-173, 2012.

[34] D. Astolfi, F. Castellani, and L. Terzi, "Fault prevention and diagnosis through SCADA temperature data analysis of an onshore wind farm," Diagnostyka, vol. 15, no. 2, pp. 71-78, 2014.

[35] J. R. Stack, T. G. Habetler, and R. G. Harley, "Effects of machine speed on the development and detection of rolling element bearing faults," IEEE Power Electronics Letters, vol. 1, no. 1, pp. 19-21, 2003.

[36] W. Yang, R. Court, and J. Jiang, "Wind turbine condition monitoring by the approach of SCADA data analysis," Renewable Energy, vol. 53, pp. 365-376, 2013.

[37] R. Zimroz, W. Bartelmus, T. Barszcz, and J. Urbanek, "Wind turbine main bearing diagnosis-a proposal of data processing and decision making procedure under non stationary load condition," Key Engineering Materials, vol. 518, pp. 437-444, 2012.

[38] Z. Hameed, Y. S. Hong, Y. M. Cho, S. H. Ahn, and C. K. Song, "Condition monitoring and fault detection of wind turbines and related algorithms: a review," Renewable and Sustainable Energy Reviews, vol. 13, no. 1, pp. 1-39, 2009.

[39] J. Urbanek, M. Strączkiewicz, and T. Barszcz, "Joint powerspeed representation of vibration features: application to wind turbine planetary gearbox," in Proceedings of the 3rd International conference on Condition Monitoring of Machinery in NonStationary Operations, Ferrara, Italy, May 2013.

[40] G. Żak, J. Obuchowski, A. Wylomańska, and R. Zimroz, "Application of ARMA modelling and alpha-stable distribution for local damage detection in bearings," Diagnostyka, vol. 15, no. 3, pp. 3-10, 2014.

[41] M. A. Timusk, M. G. Lipsett, J. McBain, and C. K. Mechefske, "Automated operating mode classification for online monitoring systems," Journal of Vibration and Acoustics, vol. 131, pp. 131141, 2009.

[42] M. Straczkiewicz, P. Wiciak, A. Jabłoński, and T. Barszcz, "Machinery in highly changing operations: on designation of operational states," in Proceedings of the 12th International Conference on Condition Monitoring and Machinery Failure Prevention Technologies, pp. 1-12, Oxford, UK, June 2015.

[43] A. Hajnayeb, S. E. Khadem, and M. H. Moradi, "Design and implementation of an automatic condition-monitoring expert system for ball-bearing fault detection," Industrial Lubrication and Tribology, vol. 60, no. 2, pp. 93-100, 2008. 
[44] B. Samanta and K. R. Al-Balushi, "Artificial neural network based fault diagnostics of rolling element bearings using timedomain features," Mechanical Systems and Signal Processing, vol. 17, no. 2, pp. 317-328, 2003.

[45] M. Cocconcelli, R. Rubini, R. Zimroz, and W. Bartlemus, "Diagnostics of ball bearings in varying-speed motors by means of artificial neural network," in Proceedings of the 8th International Conference on Condition Monitoring and Machinery Failure Prevention Technologies, pp. 760-771, Cardiff, UK, June 2011.

[46] J. Rafiee, F. Arvani, A. Harifi, and M. H. Sadeghi, "Intelligent condition monitoring of a gearbox using artificial neural network," Mechanical Systems and Signal Processing, vol. 21, no. 4, pp. 1746-1754, 2007.

[47] A. Azadeh, M. Saberi, A. Kazem, V. Ebrahimipour, A. Nourmohammadzadeh, and Z. Saberi, "A flexible algorithm for fault diagnosis in a centrifugal pump with corrupted data and noise based on ANN and support vector machine with hyperparameters optimization," Applied Soft Computing Journal, vol. 13, no. 3, pp. 1478-1485, 2013.

[48] D. V. S. S. S. Sarma and G. N. S. Kalyani, "ANN approach for condition monitoring of power transformers using DGA," in Proceedings of the IEEE Region 10 Conference (TENCON '04), vol. 3, pp. 444-447, IEEE, November 2004.

[49] Z. Tian, "An artificial neural network method for remaining useful life prediction of equipment subject to condition monitoring," Journal of Intelligent Manufacturing, vol. 23, no. 2, pp. 227-237, 2012.

[50] A. R. Bahmanyar and A. Karami, "Power system voltage stability monitoring using artificial neural networks with a reduced set of inputs," International Journal of Electrical Power and Energy Systems, vol. 58, pp. 246-256, 2014.

[51] D. Crivelli, M. Guagliano, and A. Monici, "Development of an artificial neural network processing technique for the analysis of damage evolution in pultruded composites with acoustic emission," Composites Part B: Engineering, vol. 56, pp. 948-959, 2014.

[52] Z. Zhang and K. Wang, "Wind turbine fault detection based on SCADA data analysis using ANN," Advances in Manufacturing, vol. 2, no. 1, pp. 70-78, 2014.

[53] D. E. Rumelhart, G. E. Hinton, and R. J. Williams, "Learning internal representations by error propagation," in Parallel Distributed Processing: Explorations in the Microstructure of Cognition, vol. 1, pp. 318-362, MIT Press, Cambridge, Mass, USA, 1986.

[54] A. Jablonski, T. Barszcz, M. Bielecka, and P. Breuhaus, "Modeling of probability distribution functions for automatic threshold calculation in condition monitoring systems," Measurement, vol. 46, no. 1, pp. 727-738, 2013.

[55] C. Cempel, "Limit value in the practice of machine vibration diagnostics," Mechanical Systems and Signal Processing, vol. 4, no. 6, pp. 483-493, 1990.

[56] T. Barszcz and M. Straczkiewicz, "Novel intuitive hierarchical structures for condition monitoring system of wind turbines," Diagnostyka, vol. 14, no. 3, pp. 53-60, 2013.

[57] ISO, "Mechanical vibration-evaluation of machine vibration by measurements on non-rotating parts-part I: general guidelines," ISO 10816, International Organization for Standardization, Geneva, Switzerland, 1995. 


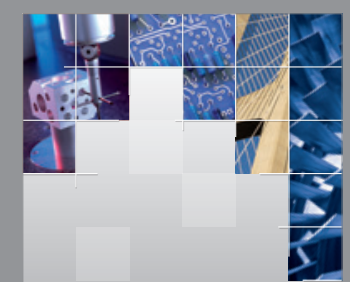

\section{Enfincering}
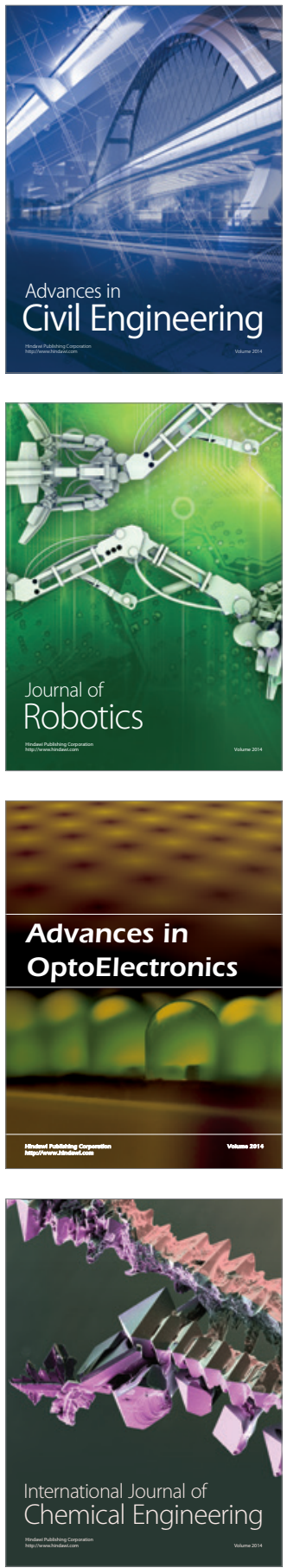

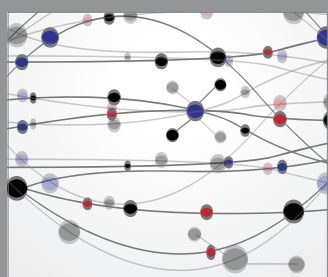

The Scientific World Journal

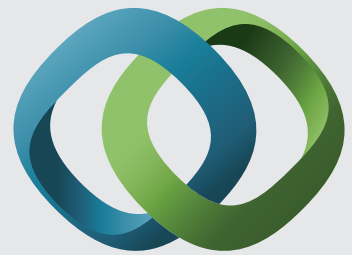

\section{Hindawi}

Submit your manuscripts at

http://www.hindawi.com
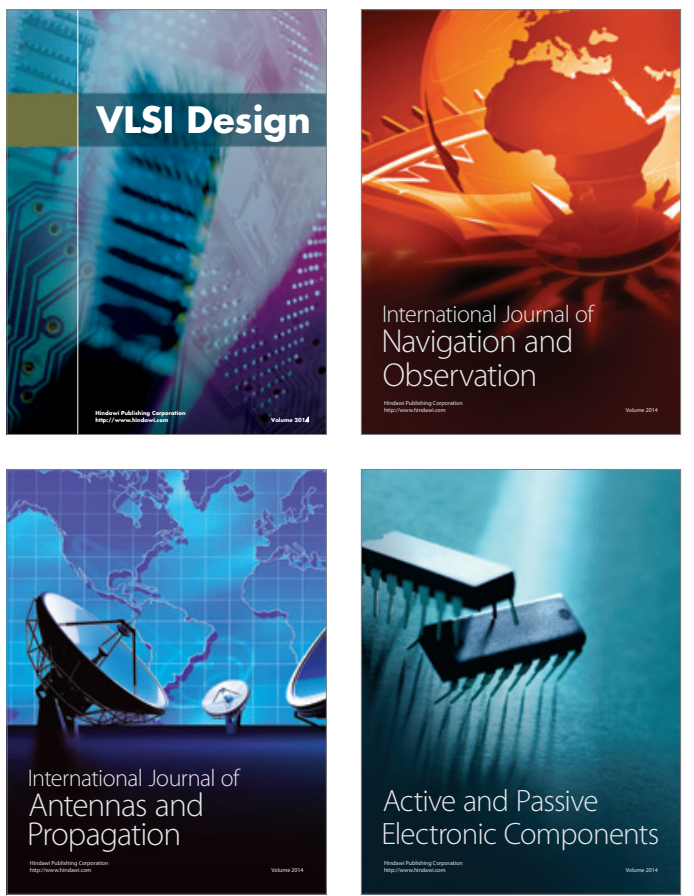
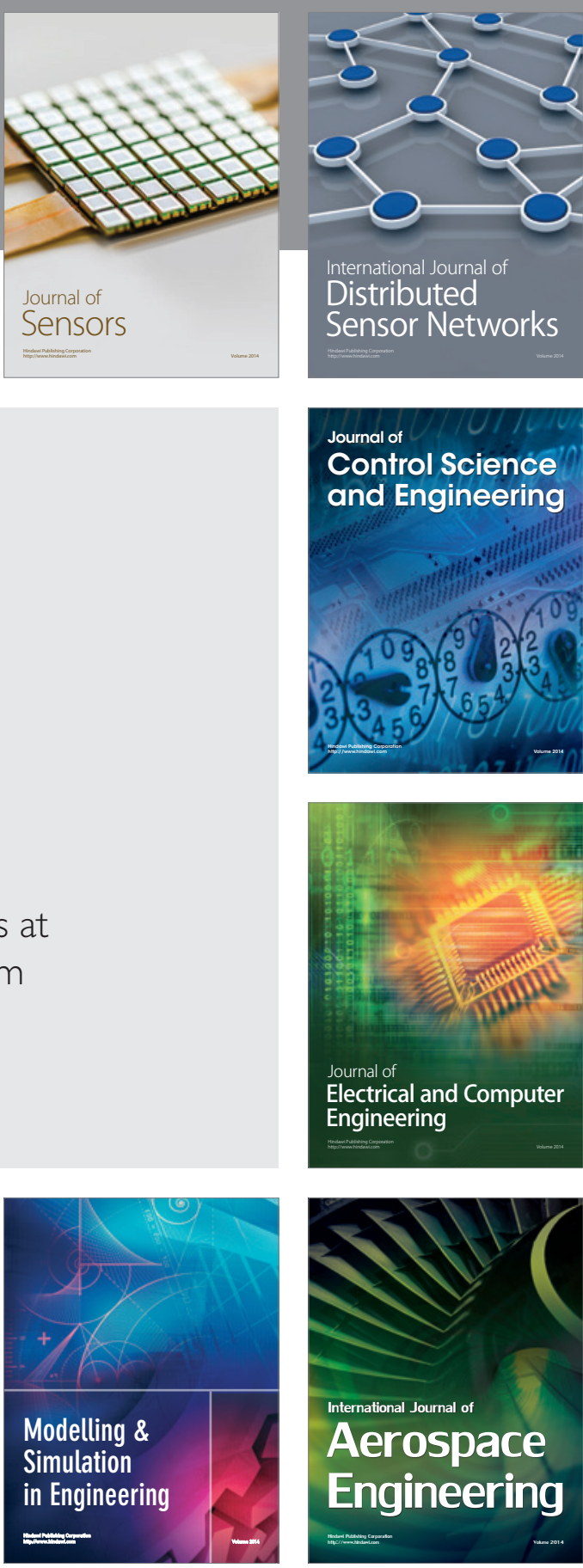

International Journal of

Distributed

Sensor Networks

Journal of

Control Science

and Engineering
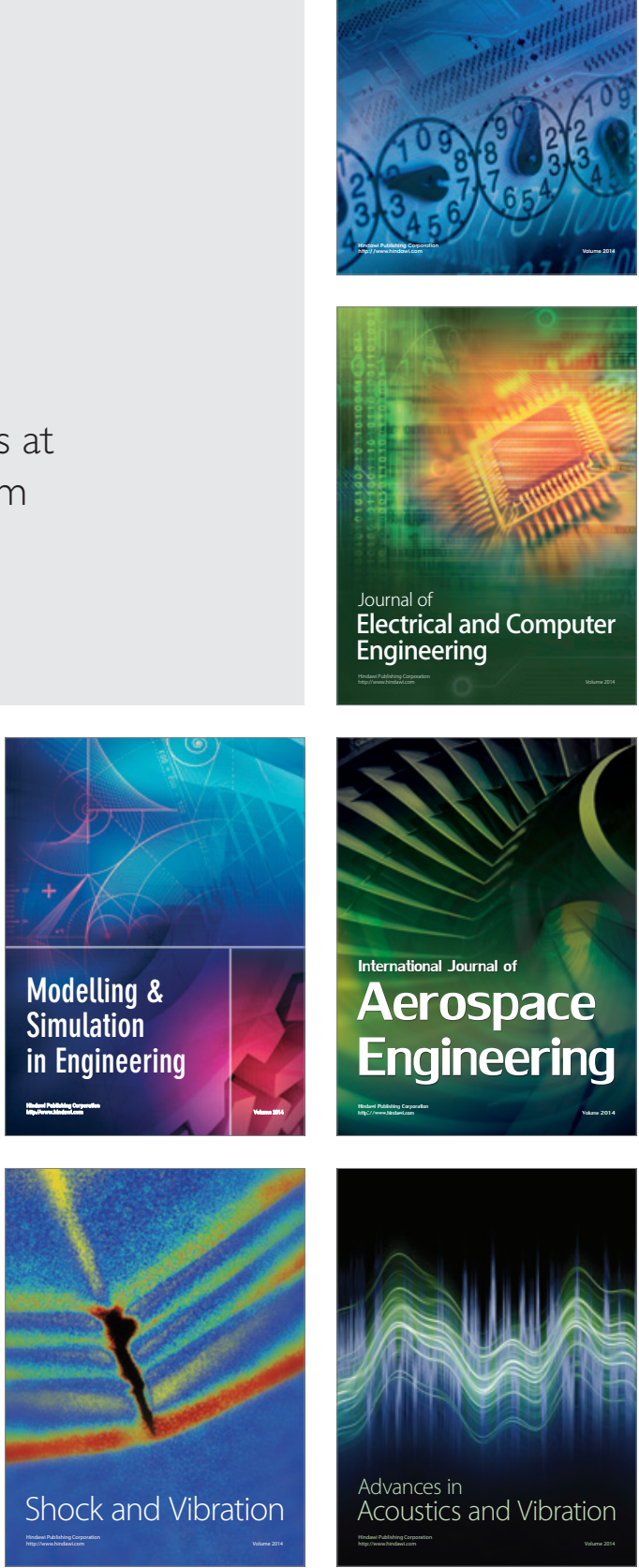